\title{
An unusual case of disease in pet fish stocks caused by Coleps sp. (Protozoa: Kinetoflagminophorea)
}

\author{
Csaba Székely' ${ }^{1}$ Magdolna Cs. Bereczky ${ }^{2}$ \\ ${ }^{1}$ Veterinary Medical Research Institute, Hungarian Academy of Sciences, PO Box 18, H-1581 Budapest, Hungary \\ ${ }^{2}$ Hungarian Danube Research Station, Hungarian Academy of Sciences, Jávorka Sándor u. 14, H-2131 Göd, Hungary
}

\begin{abstract}
In some stocks of fry of 3 aquarium fish species, Schulz's corydoras Corydoras schultzei, tiger barb Barbus tetrazona and black telescope eye goldfish Carassius auratus, 20 to $90 \%$ mortality occurred. The mortality was caused by a ciliate protozoan which did not resemble any of the known fish ectoparasites. The deaths occurred in fry kept in densely populated aquaria. The protozoans were attached to the epithelium with their cytostoma and often covered the body surface in large masses. The protozoan was identified as a Coleps sp., previously known only as a coprophagous species or a predator of protozoans. This is the first report of losses caused by a Coleps sp. in fish fry.
\end{abstract}

In spring 1991, deaths occurred in stocks of several aquarium fish species. The affected fish were 2 to $4 \mathrm{wk}$ old, 0.6 to $1.0 \mathrm{~cm}$ long fry of Schulz's corydoras Corydoras schultzei, tiger barb Barbus tetrazona and black telescope eye goldfish Carassius auratus.

Always fish of the smallest size became affected. Clinical signs occurred first on slow-growing fry in the form of slower movement and reduced feeding rate followed by emaciation and, finally, death. By microscopy, numerous medium-sized, feeding or moving ciliates temporarily fixing themselves in positon with their cytostoma were seen on the body surface and fins. These protozoans did not resemble any fish ectoparasites that had previously been known. Onset of the clinical signs was followed by deaths 1 to $2 \mathrm{~d}$ later. Mortality rates as high as 20 to $90 \%$ occurred in some stocks.

The deaths consistently occurred in densely populated fry stocks (600 to 1000 fish per $100 \mathrm{l}$ of water). The aquaria had aerated water, filtered through an internal porous filter. Until the onset of disease, the fry had been fed exclusively on Artemia salina nauplii and a powdered feed.
The protozoans were attached to the epithelium with their cytostoma (Fig, 1) and often covered the body surface and fins in large masses (Fig. 2). We assume that they may have fed not only on the epithelium but also on the bacteria present there. The ends of fins of severely infested fish often became ragged and bare. The protozoan responsible for the deaths was identified as a Coleps species, previously known in the specialized literature (Chardez 1976) exclusively as a coprophagous species or a predator of protozoa (Fig. 3). Colepses are, however, also known to prefer dying, disintegrating animal cells to other foods.

Coleps spp. are common in surface waters and are eurytopic with respect to temperature. Wilbert \& Schmall (1976) have described the morphology of Coleps nolandi as follows. The members of the genus are barrel shaped. Their body surface is covered by concentrically arranged ectoplasmic lamellae strengthened by calcic deposition. The cytostoma, which is located at the anterior end of the body, is surrounded by cilia of medium length. From the posterior end of the body one or more cilia arise and one or more posterior processes can be found there. In morphology and measurements (length 40 to $60 \mu \mathrm{m} ; 15$ to 20 ectoplasmic lamellae present on the body surface) the Coleps sp. found by us is identical with Coleps hirtus; however, the pattern of its lamellae is not fully identical with that in the 'hirtus' group. For that reason we cannot give an accurate species identification.

Coleps infection could not be controlled in the usual way, with a widely used antiprotozoal agent of proven efficacy $(3.7 \mathrm{~g}$ methylene blue and $3.7 \mathrm{~g}$ malachite green dissolved in $1 \mathrm{l}$ of formalin); we added $1.2 \mathrm{ml}$ of the agent to $100 \mathrm{l}$ aquarium water, but deaths among 


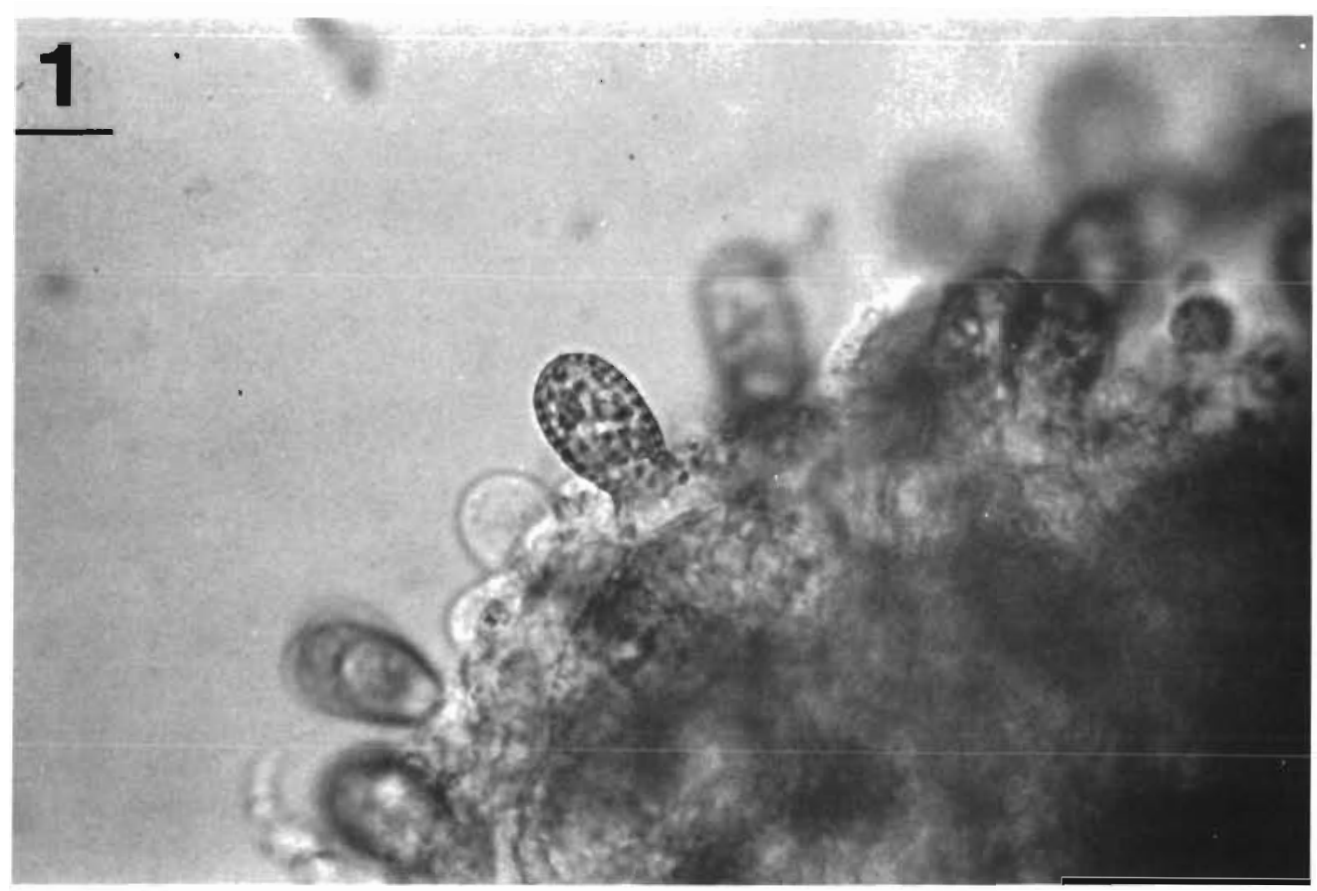

Fig. 1. Coleps sp. infecting goldfish Carassius auratus fry. Ciliates are attached to the epithelium with their cytostome. Bar $=$ $32 \mu \mathrm{m}$

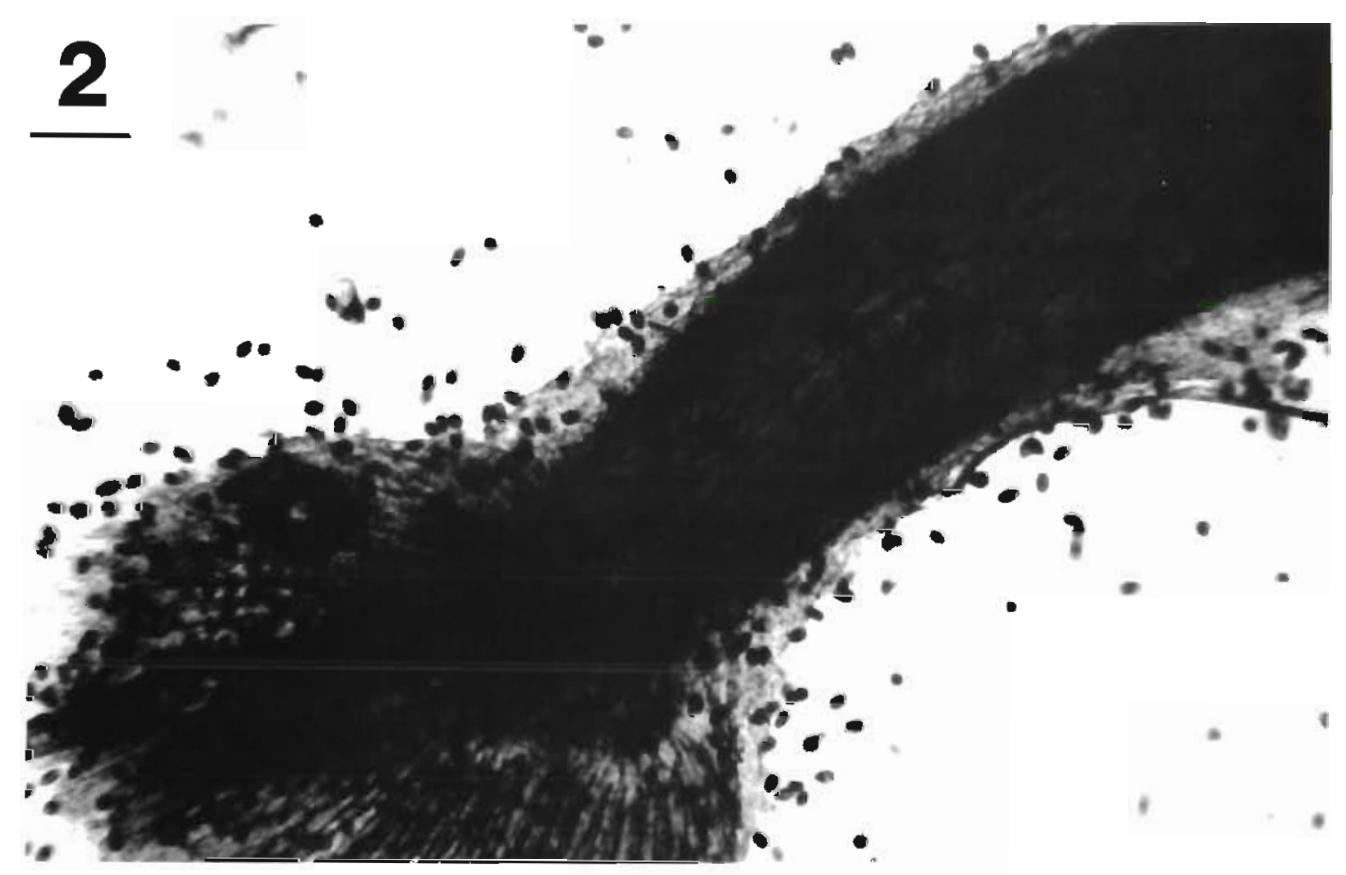

Fig. 2. Coleps sp. infecting goldfish Carassius auratus fry. Body surface and fins are covered with large masses of these protozoans. $\mathrm{Bar}=250 \mathrm{um}$ 


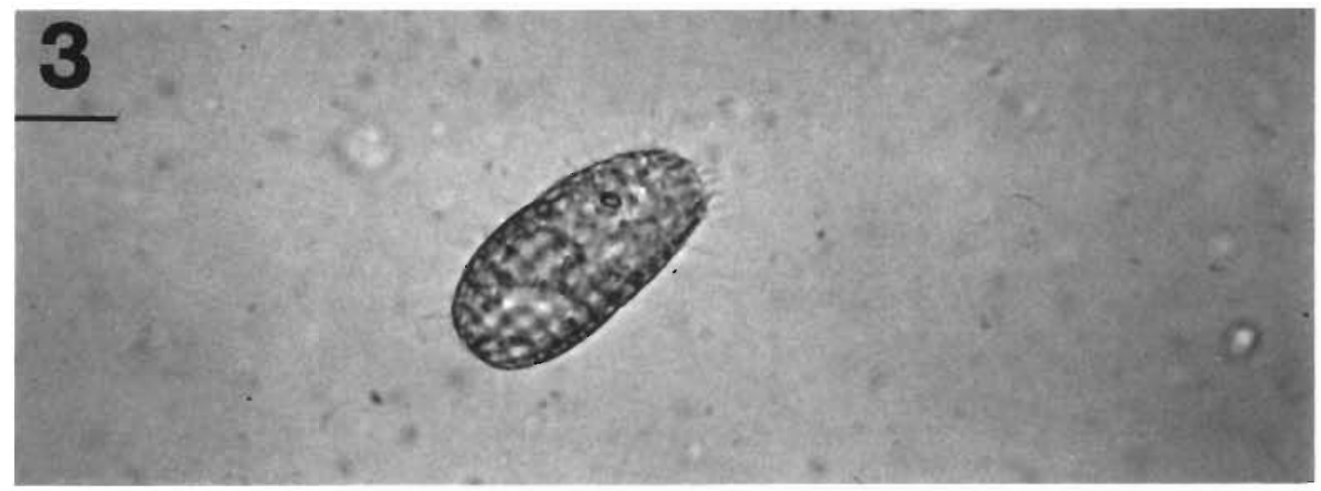

Fig. 3. Coleps sp. Detached specimen. Bar $=20 \mu \mathrm{m}$

fish of small body size continued to occur. However, stronger and larger fish survived and became free of Coleps.

On the basis of several disease processes of identical pathogenesis, we can state that in densely populated aquarium Coleps spp. may cause morbidity and mortality primarily among the weaker, smaller, severalweek-old fry. By decreasing the stocking rate, losses can be reduced. Although it has not been proven experimentally, it may be assumed that the colepses had been introduced into the stock by adhering, as cysts, to the shell of Artemia salina eggs hatched for food. Later, they became activated, multiplied, and caused deaths among the fry.

Protozoans belonging to the suborder Prorodontina are not known to be pathogenic. This paper is the first report of mortalities caused in fish fry by a Coleps sp. belonging to this suborder. Losses caused by other protozoans that cannot be considered true parasites have already been reported by other researchers; among them, Hoffman (1967) reported losses caused by

Responsible Subject Editor: W. Körting, Hannover, Germany
Ophryolegna sp. in fishes belonging to the genera Micropterus, Lepomis, Serratilus and Cottus, while Bykhovskaya-Pavlovskaya et al. (1964) and Moewus (1962) described losses caused by Tetrahymena sp. in European fishes and sea horse Hippocampus sp., respectively.

\section{LITERATURE}

Bykhovskaya-Pavlovskaya and co-authors (1964). Key to parasites of freshwater fish of the USSR. English translation. TT64-11040. U.S. Department of Commerce, off. Technical Services, Springfield, Virginia

Chardez, D. (1976). Etude sur Coleps hirtus Nitzsch (Protozoa: Ciliata). Bull. Rech. agron. Gembloux 11(1-2): 3-10

Hoffman, G. L. (1967). An unusual case of fish disease caused by Ophryolegna sp. (Protozoa: Hymenstomatida). Bull. Wildlife Dis. Ass. 3: 111-112

Moewus, L. (1962). Studies on a marine parasitic Tetrahymena species. In: Program and Abstracts, 15th Meeting of the Society of Protozoologists, Corvallis, Oregon, USA. J. Protozool. 9 (Suppl. 13): 9

Wilbert, N., Schmall, G. (1976). Morphologie und Infraciliatur von Coleps nolandi Kahl, 1930. Protistologica 12: 193-197

Manuscript first received: January 10,1992

Revised version accepted: April 29, 1992 